\title{
ФОРМИРОВАНИЕ ПОДТЕКСТА КАК ОПРЕДЕЛЯЮЩИЙ ФАКТОР РАЗВИТИЯ ХУДОЖЕСТВЕННОГО СТИЛЯ
}

\section{THE FORMATION OF SUBTEXT AS A DETERMINING FACTOR IN THE DEVELOPMENT OF AN ARTISTIC STYLE}

\section{A. Murza}

T. Alferova

Summary: The authors of the article are trying to distinguish the means of subtext creation in a literary work and their connections with the development of an artistic style.

The analysis of E. Hemingway's novels reveals that the content and coordination of the devices of psychological implication influence all parts of narration referring both to the description of the heroes' life and important social events as well as to the creator's own views and opinions shown through his characters' utterances.

Keywords: psychological implication, artistic devices, appearance and content, "an inserted novelette," narrator's speech, battle-pieces.

\author{
Мурза Александра Борисовна \\ К.филол.н., дочент, Московский Государственный \\ Университет им. М.В. Ломоносова \\ murzax@gmail.com \\ Алфёрова Татьяна Леонидовна \\ Преподаватель, Московский Государственный \\ Университет им. М.В. Ломоносова \\ t.alferova@bk.ru
}

Аннотация: Авторы статьи пытаются определить, как способы создания подтекста в литературном произведении влияют на эволюцию художественного стиля писателя.

Анализ романов Э. Хемингуэя 20-х - 30-х годов показывает, что стиль автора изменяется в зависимости от соотношения и содержания применяемых им приемов умолчания и косвенных сообщений при изображении личной судьбы героев, общественно-значительных событий и выражении его собственных взглядов.

Ключевые слова: формирование подтекста, умолчание, художественные приемы, форма и содержание, вставная новелла, речь повествователя, батальные картины.

окружающем обществе, природе и сознании людей процессов. Отсюда то сложное переплетение субъективных и объективных причин, влияющих на особенности индивидуального стиля и последовательность его эволюции. Если при постановке задач - возникновении замысла и основной идеи произведения, оформлении его темы и сюжета - объективные моменты присутствуют в виде преломленных в сознании автора реальных событий и волнующих общество вопросов, то при решении поставленных самим же автором задач содержание глав, характер сцен и особенности их участников приобретают силу объективных факторов, подсказывающих способы изображения. При этом требования художественно воплощаемого материала часто вступают в противоречие с вкусовыми пристрастиями и привычными приемами писателя, а некоторые связи становятся чисто объективными, не зависящими от его воли.

В результате совместного воздействия или борьбы субъективных и объективных причин возникают отдельные изменения формы произведения и её стилевых особенностей, накопление которых ведет к существенным сдвигам во всем стиле писателя. Несмотря на беспрерывные частные изменения, талантливый автор находит выход из создавшихся противоречий, обеспечивающий сохранение единства содержания и формы, целостность формы и стройность стиля его произведений.

Одной из наиболее заметных особенностей худо- 
жественного почерка современных творцов является стремление к косвенности сообщений. Под косвенностью сообщений мы подразумеваем все случаи умышленно неполной, незаконченной или завуалированной, содержащей умолчание передачи действующими лицами или повествователем различных сведений, выражения их мыслей и чувств. Каждый случай косвенного сообщения порождает свой частный подтекст, выявление которого производится читателем путем суммирования, сопоставления и анализа различных высказываний персонажей, замечаний повествователя и пр.

Все это рассчитано на активное прочтение произведения, способствует именно такому прочтению. Читатель неизбежно вовлекается в процесс расшифровки умолчаний, соотнесения отрывочных сведений и намеков, которые естественно вплетаются в речь повествователя, в разговоры и ход мыслей действующих лиц. Этот процесс, требуя от читателя не только сосредоточения внимания и некоторой живости воображения, но и привлечения его собственного опыта и знаний, вызывает у него ощущение подобия участия в художественном творчестве, что обеспечивает повышение увлекательности повествования и достижение высокой степени сопереживания с его героями.

В основе большинства встречающихся в литературоведении определений сущности подтекста лежит указание, что он возникает каждый раз, когда какая-то часть текста художественного произведения, кроме своего прямого значения, имеет по воле автора еще и более важный, широкий или противоречащий прямому значению, подспудный смысл, угадываемый читателем. Такое представление может быть дополнено с помощью определения подтекста в театральном искусстве, где подтекст рассматривается как комплекс мыслей и чувств, который содержится в тексте, произносимом персонажами пьесы, раскрывается актерами в паузах и внутренних (не произносимых вслух) монологах. К.С. Станиславский называл подтекст явной, внутренне ощутимой жизнью роли, "которая непрерывно течет под словами текста, все время оправдывая и оживляя их" (Литература 1).

Перенося понимание подтекста в театральном искусстве на подтекст романа, необходимо учитывать отличия последнего от драматургического произведения. Одним из таких отличий, изменяющим условия возникновения подтекста, является присутствие в художественном прозаическом произведении обращенных к читателю (а не к постановщику и исполнителям ролей) ремарок и описаний повествователя, а также развернутого текста внутренних монологов героев. Поэтому сведения и оценки, лежащие в подтексте романа (повести, рассказа) возникают не только в результате умышленной недоговоренности прямой речи, нарушения логической последовательности содержания реплик, несоответствия слов персонажей их поступкам (жестам, мимике), введения в диалог многозначительных пауз и т.п., но и в силу противоречий между смыслом высказываний действующих лиц или их поведения и освещением происходящего повествователем. При формировании подтекста романа повышается роль расхождений между словами и мыслями участников диалога, возрастает значение авторских характеристик героев, более заметных и выразительных в книге, чем на сцене, мелких материальных деталей. Словом, источником подтекста романа могут служить любые элементы повествования, из сочетания и взаимодействия которых возникают качественно новые по смыслу и эмоциональному воздействию на читателя моменты.

“Если писатель хорошо знает то, о чем пишет, он может опустить многое из того, что знает, и, если он пишет правдиво, читатель почувствует опущенное так же сильно, как если бы писатель сказал об этом" (2) - утверждает Э. Хемингуэй в известном рассуждении о "правиле айсберга". В силу постоянного стремления Хемингуэя соблюдать это правило, в его романах образуется особенно важный и обширный подтекст, который несет основную, по сравнению с потоком прямых сообщений (и более значительную, чем у других авторов), нагрузку в процессе выражения идеи произведения.

Мы постараемся проследить, как изменялось формирование подтекста в романах Э. Хемингуэя двадцатыхтридцатых годов, отмеченных особенно напряженными поисками в области стиля. В эти годы им в основном выработан тот "энергичный" стиль, который явился "достижением искусства современного повествования" (3), как это отмечено в решении о присуждении писателю Нобелевской премии.

Избранные нами романы: "И восходит солнце" ("The Sun Also Rises", 1926, в русском переводе "Фиеста"), “Прощай, оружие!" ("A Farewell to Arms", 1929) и “По ком звонит колокол" ("For Whom the Bell Tolls", 1940) - (4,5,6) - написаны с промежутком в три года и в одиннадцать лет и являются наиболее значительными произведениями, созданными писателем в период между двумя мировыми войнами. Несомненна также их взаимная связь и преемственность. Действие всех трех романов происходит в Европе - в тех странах, где Хемингуэй участвовал в военных событиях, начинал путь журналиста и писателя. Ни в одно другое крупное произведение автором не вложено столько личных впечатлений, придающих им особую взволнованность, достоверность, а до известной степени - и автобиографичность.

Героя "Фиесты" роднит с лейтенантом Генри из следующего романа (а также и с автором) участие в Первой мировой войне и ранение на итало-австрийском фронте, с героем третьего избранного нами романа - 
мечты о создании "настоящей книги", любовь к земле и простым людям Испании. Невозмутимый старый баск у пограничного моста ("Фиеста"-10/92) с годами разрастается в самоотверженного старика Ансельмо. Тема больного, страдающего матадора, начатая в первом романе (18/214), продолжается в третьем (гл. 4 и 14). Автор сам указывает на эти связи, когда заставляет Джейка Барнса вспомнить о миланском госпитале ("Фиеста"-4/31), а Роберта Джордана подумать об убитом враге: "I've probably seen him run through the streets ahead of the bulls at the Feria in Pamplona" ("Колокол"-26/279). Можно сказать, что в шутливой песенке Билла из "Фиесты", распеваемой на мотив псалма: "The Bells are Ringing for Me and My Gal..." (12/114) слышатся удары будущего “Колокола".

Однако самая крепкая и значительная связь избранных произведений лежит на уровне их глубокого подтекста. Эта связь заключается в проявлении автором в каждом из романов изменяющегося отношения к войне и борьбе народа против угнетателей. Благодаря этой неразрывной связи романы “Фиеста", “Прощай, оружие!” и "По ком звонит колокол" предстают перед нами как три вершины единого основного хребта творчества Э. Хемингуэя двадцатых-тридцатых годов. Именно изменение отношения писателя к войне, к борьбе народа против насилия и несправедливости определяет в тот период выбор им все более социально значительных сюжетов, возрастание общественной активности его героев, повышение ясности и убедительности выражения авторских взглядов на изображаемые события, что является главной движущей силой эволюции всего литературного стиля Э. Хемингуэя.

Созданию обширного и сложного общего подтекста в романах американского писателя способствует частое применение им приемов умолчания, каждый из которых рождает свой частный подтекст. Подтекст является оборотной стороной всякого умолчания. Если умолчание сознательно и искусно создается автором для достижения определенной художественной цели, то извлечение из него подтекста производится читателем, который для этого должен обладать, хотя бы в сильно уменьшенной степени, теми же качествами, что и автор. Чем глубже и значительнее подтекст, заложенный в отдельных умолчаниях, диалогах, сценах и во всем повествовании, тем в большей мере его понимание ставится в зависимость от способности читателя к восприятию и оценке деталей описания, замечаний персонажей, даже от тонких оттенков их реакции на происходящее или на слова собеседника. При недостаточном внимании или слабой подготовленности читателя ряд важных умолчаний может пройти незамеченным, а что еще хуже - быть понятым неверно.

Отсюда возникает весьма важная особенность эволюции литературного стиля Хемингуэя: по мере того, как в его романах затрагиваются все более важные, острые и сложные общественно-политические вопросы, а одновременно повышается заинтересованность писателя в том, чтобы, выразив собственные взгляды на эти вопросы, убедить читателя в своей правоте, умолчания начинает играть относительно меньшую роль среди других приемов художественной выразительности, и подтекст произведения (а, следовательно, и его основная идея) становится доступней для читателя.

В каждом из рассматриваемых романов формирование общего подтекста произведения происходит по трем основным путям:

- на примере личной судьбы героев;

- с помощью изображения общественно-значительных событий;

- посредством выражения взглядов автора на эти события в словах и мыслях действующих лиц.

От романа к роману степень использования каждого из указанных путей формирования общего подтекста заметно изменяется. Путь к общему подтексту произведения через анализ личной судьбы персонажей "Фиесты" оказывается для читателя самым длинным и трудным. Проследим этот путь на примере истории девушки Жоржет, вставная новелла о которой содержит наибольшее количество умолчаний (12 случаев на двух страницах 3/15,16). В начале главы повествователь дает понять, что Жоржет принадлежит к числу “курочек", бродящих в поисках ужина по парижским бульварам. Далее сообщения о ней носят более косвенный, завуалированный характер, причем, как это часто бывает у Хемингуэя, сначала мы узнаем о возможном будущем девушки, затем - о настоящем ее положении и наконец - кое-что о прошлом. Сгруппировав умолчания этой новеллы по смыслу и расположив их в логической последовательности, мы узнаем о Жоржет следующее.

Упоминание о фламандцах, названия городов, встречающиеся в диалоге с Джейком Барнсом, свидетельствуют о том, что прошлое Жоржет связано с Бельгией. Конечно, чтобы вывести такое заключение, читатель должен знать, в какой стране живут фламандцы, где находятся Льеж и Брюссель. Если, кроме того, он вспомнит, что во время Первой мировой войны на долю Бельгии выпали наибольшие среди западных стран испытания, что массы ее населения вынуждены были бежать из родных мест, это прольет новый свет на недавнее прошлое девушки.

Жоржет - девушка простая, малоразвитая. С этой стороны она открывается после своего “Don't kid me" - в ответ на очевидно правильное объяснение Джейка о назначении множества часов в окне редакции. Она голодна - сперва ее не удовлетворяет скромное угощение (рюмка перно), затем она веселеет от еды. Кроме того, 
она больна, о чем откровенно говорит Джейку. Характер же ее заболевания нетрудно разгадать по следующим далее репликам и в связи с ее прогулками по бульварам. Немудрено, что девушка не любит Париж, где для нее все дорого и грязно, а окружающие люди вовсе не кажутся "nice" (см. диалог с Фрэнсис - 3/19). Это ее настоящее. Что же касается будущего Жоржет, то оно безрадостно и неопределенно, как ее ответы Барнсу: "You never know in this town". "Happy, hell", "Isn't anywhere else”.

Вот достаточно законченная и типичная история простой девушки, изгнанной войной из родного дома и брошенной на парижскую панель. То, что эта история понята нами правильно, подтверждает сам автор, заставляя своего героя спросить Жоржет о Льеже, заговорить с ней о еде и возможности уехать в другое место. Однако для того, чтобы добыть эту историю из текста развернутых перед нами страниц, приходится выполнить по меньшей мере три этапа работы, преодолев несколько слоев частного подтекста. Во-первых, прочитать текст этих страниц, из которого почерпнуть прямые сведения о занятии Жоржет и ее болезни. Во-вторых, расшифровать отдельные умолчания, мысленно сгруппировав их по смыслу, сопоставив между собой и дополнив собственными знаниями. В-третьих, свести все - как прямые, так и добытые в результате расшифровки умолчаний сведения и представления в цельную историю Жоржет. Далее история Жоржет вольется в общий поток личных судеб героев "Фиесты" и вместе с ними будет решающим образом способствовать формированию общего, самого важного и глубокого (составляющего четвертый слой) подтекста романа - о пагубном влиянии империалистической войны на судьбы целого поколения людей Западной Европы и Америки.

Примерно в такой же последовательности идет осознание читателем влияния войны на судьбу других персонажей "Фиесты". Разница заключается в том, что сведения о прошлом Джейка, Брет и других действующих лиц разбросаны по всему роману, что при относительно меньшей косвенности некоторых сообщений заставляет читателя запоминать и суммировать их по мере прочтения глав.

В следующем романе “Прощай, оружие!" по степени сложности образования подтекста ближе к "Фиесте" стоят вставные новеллы о личной судьбе неизвестного солдата, истекшего кровью в санитарной машине $(9 / 75,76)$, офицера, чей пистолет приобретает Фредерик (23/141), хозяев покинутой красивой фермы (18/184). Но здесь извлечение подтекста иже не требует от читателя какихлибо его собственных знаний. Этот подтекст складывается сразу при сопоставлении образующих "новеллу" умолчаний, чтобы дополнить наше представление о страданиях, которые принесла народу империалистическая война. Еще откровенней изображены в романе такие жертвы войны, как солдат с грыжей (7/54-56), расстрелянный земляк Пассини и его семья $(9 / 65,66)$, девушки-сестры, бегущие от войны, как, наверное, бежала от нее Жоржет $(28 / 178,29 / 186,187)$. На глазах у читателя развертывается трагедия талантливого хирурга Ринальди, доведенного до нервного расстройства (гл. 25), и доброго священника, старающегося примирить то, что творится на земле, с верой в божественную справедливость (гл. 26). На протяжении всего повествования следим мы за мытарствами главных героев и закрываем книгу с твердым убеждением: что бы ни послужило непосредственной причиной неудачных родов Кэтрин - узкий таз, беспрестанные волнения, гребля в бурную ночь или роковая случайность - ее погубила война.

Что касается изображения общественно-значительных событий, то в "Фиесте" нет даже, казалось бы, неизбежных воспоминаний о боевых эпизодах и однополчанах. Завязавшийся было разговор о подвигах Майкла тотчас превращается Брет в шутку (13/134), а самым поэтичным упоминанием военного времени остается мимолетная мысль Джейка о товарищеских ужинах перед боем (конец гл. 13). Однако герои “Фиесты” живут и действуют в конкретной послевоенной обстановке. Поэтому в их речах и впечатлениях, в деталях окружающей их действительности изредка отражаются черты и события того времени. Пессимистические ответы Жоржет: "Isn't anywhere else" и пр. (3/15), фраза англичанина Харриса: "I've not had much fun since the war" (13/129) косвенно освещают тяжелые условия, сложившиеся для простых людей в странах Западной Европы. Пообедав в Байонне, Барнс замечает: "It was a big meal for France but it seemed very carefully apportioned after Spain" (19/232). Действительно, во Франции тогда еще не было восстановлено разрушенное войной хозяйство, в деревнях остро не хватало мужчин. Нейтральная же Испания не только не пострадала от войны, но извлекла выгоду от военных поставок и наплыва иностранцев. Этим, очевидно, вызван и плакат: “Hurray for the Foreigners” (15/154), который толпа несет во время праздника в Памплоне.

Косвенно упомянуты в “Фиесте" и некоторые события двадцатых годов, не имеющие прямого отношения к мировой войне и судьбам главных героев романа. Помимо иронических замечаний об испанском диктаторе Примо де Ривера (12/114) и американском реакционном деятеле, обвинителе на антидарвинистском “обезьяньем процессе" Брайане(12/121), сюда относятся слова Фрэнсис о французском военном займе, на котором ее мать потеряла свои деньги (6/49), упоминание об одноруком солдате в Сан-Себастьяне (19/237), который, как можно догадаться, изувечен в позорной и несчастливой для испанцев колониальной войне в свободной части Марокко. Понятно, что подобные разрозненные, до предела краткие и требующие от читателя обязательного знакомства с международной обстановкой тех лет, сообщения 
“Фиесты", мало способствуют формированию ее общего подтекста.

Если в первом исследуемом произведении мировая война присутствует незримо, как нечто ушедшее в прошлое, то в романе "Прощай, оружие!" непосредственному изображению военных событий, картин отступления итальянской армии и бегства мирного населения отведено свыше трети текста (по количеству слов). В диалогах романа содержатся сведения о ходе войны (21/130, 25/154, 27/167 и т. д.), обсуждается настроение итальянских солдат и вопросы внутреннего положения воюющих сторон (7/55, 9/65-67, 26/164-166, 27/169, 35/229, 230 и др.). Действующие лица "Фиесты”, независимо от их социального положения, в равной мере испытали опасности войны и теперь ощущают разрушительное ее действие на материальную сторону существования и духовный мир людей.

Батальные картины романа "Прощай, оружие!" дают нам многочисленные нити, прямо ведущие к общему подтексту произведения, способствующему убеждению читателя в безнравственности, чудовищности войны, цели которой не отвечают интересам народа. Общественная позиция героя “Фиесты” проявлялась всего лишь в ироническом тоне упоминания реакционных деталей. Фредерик Генри высказывает свое мнение несколько более определенно. При этом его характер, духовный мир, взгляды на происходящее под влиянием пережитого изменяются на протяжении повествования в большей мере, чем у героев других рассматриваемых произведений (чему благоприятствует и большая протяженность времени действия романа “Прощай, оружие!"). В начале романа Фредерик, хотя и признает, что война - страшная вещь (9/67), но призывает довести ее до конца. К концу батальной части повествования он доходит до признания способности крестьян управлять государством (26/165) и высказывает сожаление о том, что солдаты, не желающие воевать, бросая винтовки, остаются безоружными перед своими угнетателями (30/198). Однако эти высказывания делаются в форме коротких отрывистых реплик, не исключающих возможность двоякого их понимания.

В ряде мест романа “Прощай, оружие!" лейтенант Генри просто уходит от прямого ответа на вопрос о своих взглядах на империалистическую войну и связанные с ее ведением проблемы. Когда священник спрашивает Фредерика: "What do you believe in?", тот отделывается шуткой (26/166). Промолчит герой и тогда, когда офицер Джино попытается оправдать продолжение войны (27/169). Что касается разговора с графом Греффи, то в нем больше внешнего блеска, чем глубоких и справедливых мыслей о войне (35/230). Таким образом, несмотря на заметное возмужание и созревание его убеждений к концу романа, Фредерик так и не успевает почувство- вать себя активным борцом против насилия и несправедливой войны, а его высказывания по степени своего воздействия на читателя уступают не только батальным сценам романа, но и событиям личной жизни героев.

Национально-революционная война испанского народа показана в романе "По ком звонит колокол" в самых различных ее проявлениях, одни из которых свидетельствуют о несомненной правоте республиканской стороны и ее потенциальной способности победить, другие же затрагивают те ошибки и трудности, которые мешали победе Республики и усиленно использовались ее врагами для обработки мирового общественного мнения. Автор "Колокола" старается сохранить беспристрастность при изображении событий и тем достигнуть большей убедительности выводов, которые складываются у читателя. Беспристрастность эта выражается в соблюдении примерного количественного равенства между сценами и рассказами, говорящими в пользу Республики, и теми, в которых оттеняются ее недостатки. Так, большой рассказ Пилар о расправе над фашистами (гл. 10) уравновешивается рассказами Марии (гл. 31), Хоакина $(11 / 131,132)$, воспоминаниями Роберта Джордана $(11 / 128)$ и т. д. Личное отношение автора к событиям не влияет и на качество их изображения. С одинаковой глубиной проникновения и человечностью Хемингуэй описывает конец "guardia civiles" (10/97) и смерть родителей Марии (31/323), гибель убитого Робертом Джорданом всадника $(21 / 247,26 / 279)$ и последние минуты самого героя (43/427-432). В “Колоколе" писатель избегает приукрашивания друзей и оглупления или очернения врагов (хотя анархисты в гл. 10 и 36 вызывают у него законное омерзение, а Массарт (Марти) в гл. 42 - негодование).

В таких условиях для правильного (с точки зрения автора) формирования в сознании читателя общего подтекста произведения решающее значение приобретает выражение взглядов писателя на изображаемые события, авторская аргументация, заключенная в словах и мыслях действующих лиц. Хемингуэй остается беспристрастным только при изображении событий народнореволюционной войны в Испании. Когда же дело доходит до оценки этих событий, он не только прямо высказывает свое мнение (через Роберта Джордана или одного из других персонажей романа), но и всячески отстаивает свою правоту. Количественно и качественно пропорционально показав ожесточение обеих сторон, писатель затем решительно бросает свое мнение на чашу весов, склоняющуюся в пользу простого народа Испании: "I know that we did dreadful things to them too. But it was because we were uneducated and know no better. But they did that on purpose and deliberately. Those who did that are the last flowering of what their education has produced" (31/327). Пилар весьма определенно говорит о дореспубликанской Испании: "In a country where the bourgeoisie overeat so that their stomachs are all ruined,... and the poor 
are hungry from their birth till the day they die" (14/174). В ожидании нестерпимой боли и появления врага сам герой настаивает на важности борьбы в Испании для поражения фашизма во всем мире: "If we win here we will win everywhere" (43/428).

Несмотря на то, что мнение автора “Колокола" высказывается в словах и мыслях героев по самым различным поводам (что делает неизбежным суммирование и сопоставление этих высказываний, а порой и расшифровку умолчаний), оно всегда касается сущности изображаемых событий, ярко освещает данные в романе картины народно-революционной войны и, таким образом, непосредственно или через подтекст решительно подкрепляет основную идею произведения.

Большое значение для выявления идеи и формирования подтекста романа “По ком звонит колокол" имеют пронизывающие его от начала до конца смысловые линии, посвященные всестороннему рассмотрению важных политических и морально-эстетических вопросов борьбы в Испании. Они проявляются то в виде красочных картин событий, в которых персонажи романа обычно принимают активное участие, то в форме размышлений героя по поводу этих событий. Одним из результатов воздействия на читателя различных сцен, рассказов и внутренних монологов или воспоминаний, объединенных в смысловых линиях романа, является многогранность его общего подтекста.

Несмотря на эту многогранность подтекста романа, разнообразие путей и приемов его выявления, сумма прямых и косвенных сообщений, способствующих фор- мированию этого подтекста, оказывается настолько значительной, что он откладывается в сознании читателя с полной определенностью. Высокохудожественная, эмоционально напряженная форма, в которую облечены сообщения, простота, мужество и благородство героев вместе с хорошей аргументацией их доводов и рассуждений убеждают читателя в правильности заключенного в подтексте романа решения затронутых вопросов.

Замечательная черта общего подтекста романа "По ком звонит колокол" - его жизнеутверждающая, оптимистическая направленность, казалось бы, противоречащая суровому, даже мрачному характеру изображаемых событий и трагическому концу героя. На протяжении всего повествования эта оптимистическая направленность создается жизнерадостными сценами любовных встреч с Марией, крепнущим товариществом героя с партизанами - простыми людьми Испании, его всепреодолевающим продвижением к выполнению задания и постоянной близостью с величественной природой. В последних главах романа оптимизм его подтекста питается глубокой уверенностью генерала Гольца (42/393) и Роберта Джордана (43/429) в необходимости того, что они делают для победы прогрессивных сил во всем мире.

Общий подтекст романа "По ком звонит колокол", в силу его важности, многогранности, оптимистического звучания и в то же время доступности для читателя, способствует тому, что значение этого произведения Э.Хемингуэя расширяется далеко за пределы изображения частных эпизодов народно-революционной войны в Испании, а заложенные в нем идеи приобретают глубокий, непреходящий смысл.

\section{ЛИТЕРАТУРА}

1. Станиславский К.С. Работа актера над собой. М., 1951, с.492

2. Э. Хемингуэй. Избранные произведения в двух томах. ГИХЛ, Москва, 1959, с.188

3. Anthology of American Literature. General Editor George McMichael. New York,1994, c. 145

4. The Sun Also Rises, N.Y., Scribner, 1926

5. A Farewell to Arms, N.Y., Scribner, 1929

6. For Whom the Bell Tolls. N.Y., Scribner, 1940 .

( ) Мурза Александра Борисовна (murzax@gmail.com ), Алфёрова Татьяна Леонидовна (t.alferova@bk.ru) Журнал «Современная наука: актуальные проблемы теории и практики» 